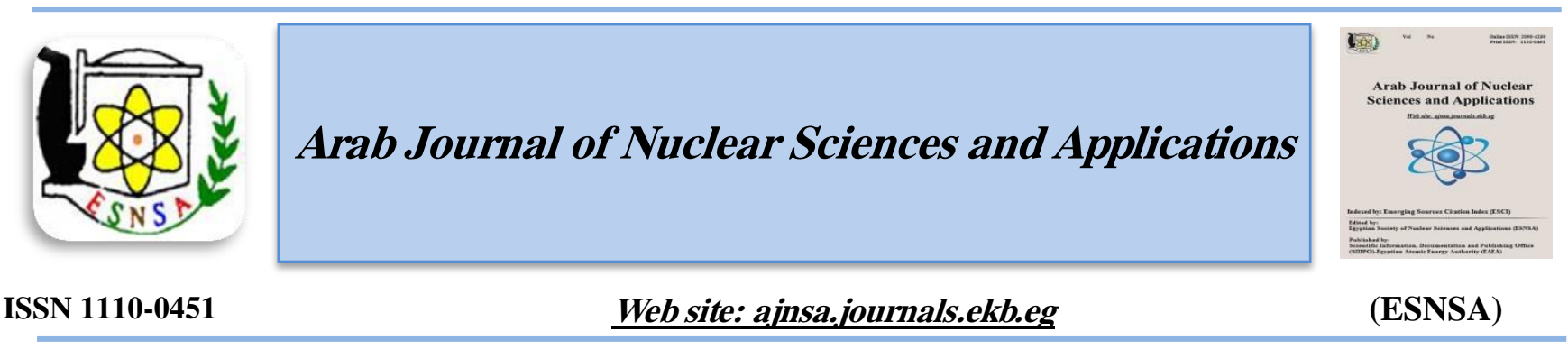

\title{
Analyze the Effect of Void Fraction on the Main Operating Parameters of the VVER-1200
}

\author{
Ahmed Abdelghafar Galahom \\ Higher Technological Institute, $10^{\text {th }}$ of Ramadan City, Egypt
}

Received $14^{\text {th }}$ Oct. 2018 The VVER-1200/AES-2006 is one of the most promising nuclear reactors for power generation. This Accepted $2^{\text {nd }}$ Sept. 2019 work provides an in-depth analysis of the void fraction effect on the operation of VVER-1200 using MCNPX code. The void fraction in the VVER-1200 may be a result from the loss of coolant accident (LOCA) or boiling the moderator/coolant materials. The fission multiplicities (v), the estimated of the recoverable energy per fission $(Q)$ and the effective delayed neutrons fraction $\left(\beta_{\text {eff }}\right)$ have been investigated at different fuel enrichment and a different void fraction. It is beneficial to calculate the $\beta_{\text {eff }}$ at the different void fraction and different enrichment, due to its impact on the reactor power change rate. The excess reactivity in the reaction can be controlled using the gadolinium dioxide or boron carbide. Increasing the void fraction decrease the burnup rate of gadolinium dioxide and boron carbide in the VVER-1200 assembly. The Doppler coefficient has a large effect on the reactivity of the reaction. Therefore, it is important to calculate the Doppler coefficient at different fuel temperature. The existence of the void fraction increases the concentration of the most hazardous radioactive nuclear waste products.

Keywords: VVER-1200- Void fraction- LOCA-Delayed neutrons- Doppler effect- Spent fuel.

\section{Introduction}

Light water reactors (LWRs) are the main suppliers of nuclear electricity. The VVER reactors belong to the family of the pressurized water reactors [1]. The VVER-1200/AES-2006 is the evolution of the VVER-1000 by improving plant performance and increasing plant safety. The VVER-1200 is one of the most promising Generation +III reactors. The main goal in the evolutionary development process of VVER-1000 to VVER-1200 was to reduce costs without substantially changing the basic configuration of the nuclear steam supply system, while at the same time increasing safety. The thermal power was increased to $3200 \mathrm{MWt}$ and additional passive safety systems introduced for the management of beyond design basis accidents. The VVER 1200 will produce $1200 \mathrm{MWe}$ of power.
The VVER-1200 design is based on the principle of safety assurance for the personnel, population and environment. The principle meets the requirements for the standards of radioactive substance release into the environment and their content at normal operation, at anticipated operational occurrences including the design basis conditions. Safety features include a containment building and missile shield. It has full emergency systems that include an emergency core cooling system, emergency backup diesel power supply, advanced refueling machine, computerized reactor control systems and backup feed water supply. The nuclear reactor and associated systems are in a single building with another building for the turbogenerators. The main building comprises the reactor, refueling machine and diesel backup power supply, steam generators and reactor control

Corresponding author: galhom 20102000@yahoo.com

DOI: 10.21608/ajnsa.2019.5643.1128

(C) Scientific Information, Documentation and Publishing Office (SIDPO)-EAEA 
systems. There are two families of VVER1200/AES-2006 plant designs; the first is the V$392 \mathrm{M}$ version that was developed by Moscow Atomenergoproekt on the basis of the AES-92 design. The other family of VVER-1200/AES2006 designs, the V-491 version, was developed by St Petersburg Atomenergoproekt on the basis of the AES-91 design developed for China, as successfully deployed at Tianwan [2].

The LOCA is postulated to occur as a break between the reactor vessel and the main circulation pump. The break results in the continuous, uncontrolled loss of reactor coolant to the containment or the auxiliary/turbine building. The LOCA is considered one of the main important design basis accidents for the LWRs. To mitigate the consequences of LOCAs from the pipe break, the emergency core cooling system is usually activated in LWRs to maintain the core inventory and remove the decay heat during all phases of the accident. Without an adequate source of emergency cooling water, the subsequent fuel heat up could result in fuel damage and the release of fission products from the fuel [3, 4]. Safe operation of nuclear power plants is assured by maintaining basic safety functions such as reactivity control, fuel cooling, and confinement. Among these functions, fuel cooling is the chief function that can maintain the thermal integrity of fuel channels in a pressurized heavy water reactor during event progression of a large break loss-of-coolant accident [5].

In VVER-1200 using boron carbide $\left(\mathrm{B}_{4} \mathrm{C}\right)$ / gadolinium dioxide $\left(\mathrm{Gd}_{2} \mathrm{O}_{3}\right)$ and varying its concentration with time serves to compensate for excess reactivity. Burnable poisons (BP) embedded in the fuel or other core constituents offer an additional means for limiting excess reactivity as well as mitigating localized power peaking. Burnable absorber (BA) is one of the most important control elements in with respect to the nuclear reactor safety. Boron carbide and boron steel are currently used in control rods of Russian power water reactors. These absorber materials accumulate large radiation-induced damages caused by $(n, \alpha)$ reactions on ${ }^{10} B$ isotopes, helium formation and swelling. The first failure of the rod cluster control assembly of VVER-1000 caused by $\mathrm{B}_{4} \mathrm{C}$ swelling [6]. The performance of $\mathrm{B}_{4} \mathrm{C}$ and $\mathrm{Gd}_{2} \mathrm{O}_{3}$ was also analyzed in this study.

Large quantities of nuclear waste plutonium and long-lived radioactive actinides have been accumulated in the LWRs using conventional fuel. Transmuted uranium (TRU) elements represent the most hazardous radioactive nuclear waste products because of their long-term, high-level radioactivity. Plutonium constitutes the majority and most dangerous component of nuclear waste. Plutonium component has serious hazard potential because of the high radio-toxicity and high radioactivity [7]. There is a great efforts have been made to reduce the inventory of long-lived radioactive actinides resulting from the fuel burning process in LWRs. Most of these TRU elements are fissionable and thus can be considered as fissile fuel materials in the form of mixed fuel with thorium or natural uranium in the latter. Therefore, it is important to study the stockpiled of the TRU elements resulting from the burning process of conventional fuel $\left(\mathrm{UO}_{2}\right)$ under different condition.

\section{Description of the reactor}

The VVER-1200/AES-2006 reactor is a pressurized water moderated reactor that consists of 163 fuel assemblies. Each fuel assembly includes 311 fuel rods, 18 guide channels and one tube for instrumentation. The control and the burnable absorber rods have been placed in the guiding channels. The model of the fuel assembly is shown in Fig. 1. The main reactor operating conditions and design parameters are presented in Table 1 [1]. The fuel assemblies of VVER-1000 and VVER-1200 are actually identical in design. Both fuel assemblies comprise a top nozzle, bottom nozzle, and the bundle of fuel elements in a rigid welded framework. They only differ in the fuel column height $353 \mathrm{~cm}$ for VVER-1000 and $375 \mathrm{~cm}$ for VVER-1200. All calculations were performed with a three-dimensional transport and depletion computer code MCNPX 2.7 code. The Monte Carlo technique can be beneficial. Since the Monte Carlo method simulates individual particle tracks through a given system, it can provide a very accurate probabilistic transport solution.

\section{Results and Discussion}

The fuel elements in the VVER-1200 core are modeled exactly, including all gaps and zircaloy cladding. The VVER-1200 assemblies are modeled at the beginning of life (BOL). The output results of the MCNPX model was calculated with standard deviation \pm 0.00021 . 
Table (1): Characteristics and dimensions of VVER-1200 core [1, 8].

\begin{tabular}{lc}
\hline \multicolumn{1}{c}{ Parameter } & Value \\
\hline Core & \\
Reactor thermal power $(\mathrm{MWt})$ & 3200 \\
Reactor electrical power $(\mathrm{MWt})$ & 1200 \\
Number of fuel assembly in the core & 163 \\
Coolant temperature at the reactor inlet $\left({ }^{\circ} \mathrm{C}\right)$ & $298 \pm 2.5$ \\
Average coolant temperature at the reactor outlet $\left({ }^{\circ} \mathrm{C}\right)$ & $329 \pm 5.0$ \\
Active core diameter $(\mathrm{cm})$ & 316 \\
Active core height $(\mathrm{cm})$ & 375 \\
Refueling frequency $(\mathrm{months}$ & $12(18)$ \\
Primary coolant temp. at core inlet $\left({ }^{\circ} \mathrm{C}\right)$ & 298.2 \\
Primary coolant temp. at core outlet $\left({ }^{\circ} \mathrm{C}\right)$ & 328.9 \\
Primary coolant pressure at reactor vessel outlet $(\mathrm{MPa})$ & 16.2 \\
Feed water temperature at SG inlet $\left({ }^{\circ} \mathrm{C}\right)$ & 225 \\
Assembly & \\
Fuel assembly form & $\mathrm{Hexagonal}$ \\
Pitch between the assemblies & 23.6 \\
Number of fuel rod in the fuel assembly & 311 \\
Number of guide tubes & 18 \\
Fresh fuel assembly enrichment & $1.6 \%, 2.4 \%, 3.6 \%$ \\
Fuel rod & \\
Hole diameter in the fuel pellet $(\mathrm{mm})$ & 1.5 \\
Fuel pellet outside diameter $(\mathrm{mm})$ & 7.57 \\
Cladding inside diameter $(\mathrm{mm})$ & 7.73 \\
Cladding outside diameter $(\mathrm{mm})$ & 9.1 \\
Fuel rod pitch (mm) & 12.75 \\
Fuel pellet material & $\mathrm{UO}{ }^{2}$ \\
Cladding material & $\mathrm{Zlloy}+1 \% \mathrm{Nb}$ \\
Fuel pellet density $\left(\mathrm{g} / \mathrm{cm}{ }^{3}\right)$ & $10.4-10.7$ \\
\hline
\end{tabular}

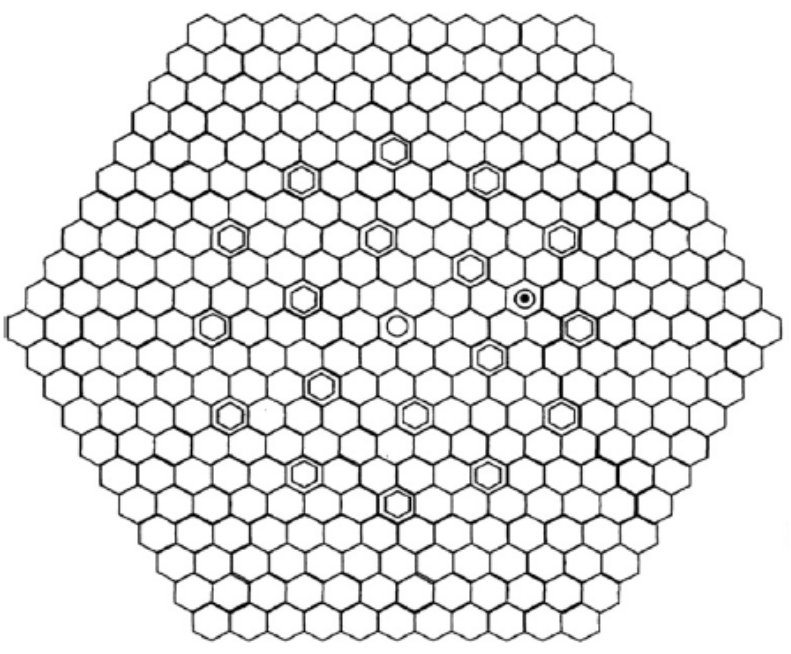

Fig. (1): VVER-1200 assembly configuration 
The fuel is ceramic uranium dioxide pellets $\left(\mathrm{UO}_{2}\right.$ with a melting point of $2800{ }^{\circ} \mathrm{C}$ ). Four types of enriched fuels $(1.6 \%, 2.4 \%, 3.6 \%$ and $4.95 \%)$ are used in designing the VVER-1200 core. The cylindrical pellets are then put into tubes of a corrosion-resistant zirconium metal alloy plus $1 \%$ $\mathrm{Nb}$ which are back filled with helium to aid heat conduction. Sintered $\mathrm{UO}_{2}$ pellets with different enrichment are stacked inside the cladding. Fig.2 illustrates a horizontal cross-section of the VVER1200 core modeling. Table 2 describes the ten different types of fuel assemblies. To control and maintain the safety of the reactor, groups of control rod are employed. The locations of the control rod groups in the reactor assembly are shown in Fig. 3, where the control rods are inserted in the guide tube. The multiplication factor $\mathrm{K}_{\mathrm{inf}}$ values for the different fuel enrichments suggested have been investigated as illustrated in Fig. 4 it is observed that the $K_{\text {inf }}$ values increase when the fuel enrichment increases. The $K_{\text {inf }}$ values for different fuel enrichments decreases with burnup until reaching steady state at which the rate of ${ }^{235} \mathrm{U}$ burnt equal to the rate of ${ }^{239} \mathrm{Pu}$ gained. In the VVER-1200 assembly, boron carbide is used in the guide tube to manage the excess reactivity. Fig.5 illustrates the variation of the $K_{\text {inf }}$ values for different fuel enrichment at different $\mathrm{B}_{4} \mathrm{C}$ concentration. The ability of $\mathrm{B}_{4} \mathrm{C}$ to absorb the thermal neutrons prevents more fission reaction occurs. Therefore, the presence of the $\mathrm{B}_{4} \mathrm{C}$ in the guide tube decreases the $\mathrm{K}_{\mathrm{inf}}$ values of the assembly. The insertion of the $\mathrm{B}_{4} \mathrm{C}$ rod with $20 \%$ decreases the $K_{\text {inf }}$ values by $390 \mathrm{pcm}$, while in the case of $36 \%$ decreases by $928 \mathrm{pcm}$.

The variation of the $K_{\text {inf }}$ values of the core with burnup is illustrated in Fig.6. The core performance is estimated from the assembly burnup analysis assuming a 10-batch fuelmanagement. The average $\mathrm{K}_{\mathrm{inf}}$ of the core can be calculated from equation 1 .

$$
\mathrm{K}_{\text {inf }}=1 /\left(\mathrm{f}_{1} / \mathrm{k}_{\text {inf }, 1}+\mathrm{f}_{2} / \mathrm{k}_{\text {inf }, 2}+\mathrm{f}_{3} / \mathrm{k}_{\text {inf }, 3}+\ldots+\mathrm{f}_{\mathrm{i}} / \mathrm{k}_{\text {inf, }, \mathrm{n}}\right) \ldots
$$

Where $\mathrm{n}$ is the number of batches, $\mathrm{k}_{\mathrm{inf}, \mathrm{i}}$ is the multiplication value calculated from the unit cell for the batch $i$ and $f_{i}$ is the fraction of the total core power generated by batch $i$. The value of $f_{i}$ can be determined from a 3-D analysis of a representative core. The attainable discharge burnup is the burnup of the fuel at the EOC from the $n^{\text {th }}$ batch.
The thermal neutron flux is the main responsible for the fission chain reaction in light water reactor. Therefore, it is important to investigate the thermal neutron flux distribution through the fuel assembly. The radial thermal neutron flux $(\mathrm{E}<0.625 \mathrm{ev})$ visualization for VVER-1200 assembly fueled with $\mathrm{UO}_{2}$ with enrichment $4.95 \%$ is presented in Fig. 7. The Local thermal flux peaks inside the control rod tubes that are filled with water when they are pulled out. This is because of the ability of the hydrogen atoms to reduce the energy of the fast neutrons that produce from the fission reaction. The radial total power distribution is presented in Fig. 8 it can be seen that there is no power in the position of the control rod that is filled with water. The power values of the fuel rods near the water rods are larger than other fuel rods due to their subjection of a large number of thermal neutrons

MCNPX code has been used to calculate the $v$ and $Q$ value in the VVER-1200 assemblies at different conditions. MCNPX takes the prompt recoverable energy per fission (Q-prompt) and multiplies that value by the constant normalization factor that was calculated by dividing $200 \mathrm{MeV}$ by the prompt fission energy release of ${ }^{235} \mathrm{U}$. The $\beta_{\text {eff }}$ is determined in order to quantify the contribution of delayed neutrons to the fission as safety and control measurement. The presence of delayed neutrons plays a significant role in reactor control due to its impact on reactor power change rates. The effective delayed neutron fraction $\left(\beta_{\text {eff }}\right)$ can be calculated using equation 2 .

$\beta_{\text {eff }}=1-\left(\frac{K_{P}}{K}\right)$

Where $k$ is the total effective eigenvalue for both prompt and delayed neutrons and $k_{p}$ is the effective prompt eigenvalue. Both eigenvalues can be obtained from the straight calculation mode of MCNPX [9]. Table 3 illustrates the main neutronic parameters of the VVER-1200 assembly at different fuel enrichment. By analyzing these results, the values of $v, Q$-value and the $\beta_{\text {eff }}$ were found to decrease as the fuel enrichment percentage increased. This is because, the concentration of the produced $\mathrm{Pu}$ isotopes at low fuel enrichment is higher than that produced at high fuel enrichment as illustrated in Fig.9. ${ }^{238} \mathrm{U}$ is the main responsible for the formation of $\mathrm{Pu}$ and its isotopes. At low fuel enrichment, a large quantity of ${ }^{238} \mathrm{U}$ is more subject to thermal 
neutrons than at higher fuel enrichment so the concentration of the ${ }^{238} \mathrm{U}$ consumed per initial heavy material (IHM) in the case of FA1 is larger than that consumed in the case of FA2 as illustrated in Fig.10. With the onset of nuclear fission, the concentration of ${ }^{235} \mathrm{U}$ per IHM decreased with fuel burnup as illustrated in Fig.11 and the $\mathrm{Pu}$ isotopes are produced. In the case of ${ }^{235} \mathrm{U}$ and ${ }^{238} \mathrm{U}$, the total neutron yield per fission is $2.4355 \pm 0.0023$ and $2.819 \pm 0.020$ respectively, while in the case of ${ }^{238} \mathrm{Pu},{ }^{239} \mathrm{Pu},{ }^{240} \mathrm{Pu},{ }^{241} \mathrm{Pu}$ and
${ }^{242} \mathrm{Pu}$ is $3.00 \pm 0.14,2.8836 \pm 0.0047,3.086 \pm$ $0.025,2.9479 \pm 0.0055$ and $3.189 \pm 0.035$ respectively. Therefore, the $v$ values increase as the fuel enrichment decreases. Also, the $\beta_{\text {eff }}$ values decrease with increasing the fuel enrichment. This is due to the formation of $\mathrm{Pu}$ isotopes and the deformation of ${ }^{235} \mathrm{U}$. The delayed neutron yield in case of ${ }^{235} \mathrm{U},{ }^{238} \mathrm{Pu},{ }^{239} \mathrm{Pu},{ }^{240} \mathrm{Pu},{ }^{241} \mathrm{Pu}$ and ${ }^{242} \mathrm{Pu}$ is $0.0162 \pm 0.0005,0.0047 \pm 0.0005,0.0065 \pm$ $0.0003,0.0090 \pm 0.0004,0.0160 \pm 0.0008$ and 0.0183

$\pm$

0.0010 .

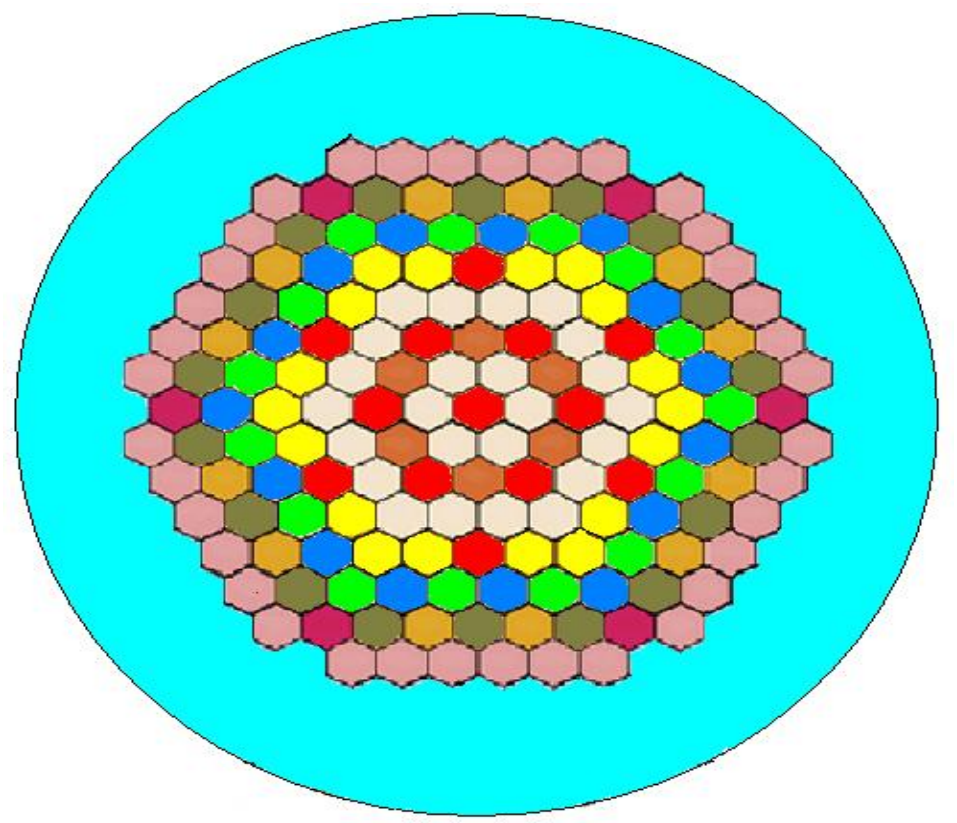

Fig. (2): Horizontal cross-section of the VVER-1200 core modeling

Table (2): Description of the ten different types of the fuel assemblies

\begin{tabular}{cccccc}
\hline Color & Fuel type & Fuel enrichment $(\%)$ & $\begin{array}{c}\text { No. burnable poison } \\
\left.\text { (boron content, g/cm }{ }^{3}\right)\end{array}$ & Symbol & $\begin{array}{c}\text { No. } \\
\text { assembly }\end{array}$ \\
\hline 16 & 1.6 & ----- & FA1 & 24 \\
24 & 2.4 & ----- & FA2 & 13 \\
36 & 3.6 & ----- & FA3 & 18 \\
4.95 & 4.95 & --- & FA4 & 36 \\
$24 \mathrm{~B} 20$ & 2.4 & $18(0.020)$ & FA5 & 6 \\
24B36 & 2.4 & $18(0.036)$ & FA6 & 18 \\
36B36 & 3.6 & $18(0.036)$ & FA7 & 15 \\
36B20 & 3.6 & $18(0.020)$ & FA8 & 12 \\
49B20 & 4.95 & $18(0.020)$ & FA9 & 6 \\
49B36 & 4.95 & $18(0.036)$ & FA10 & 15 \\
\hline
\end{tabular}




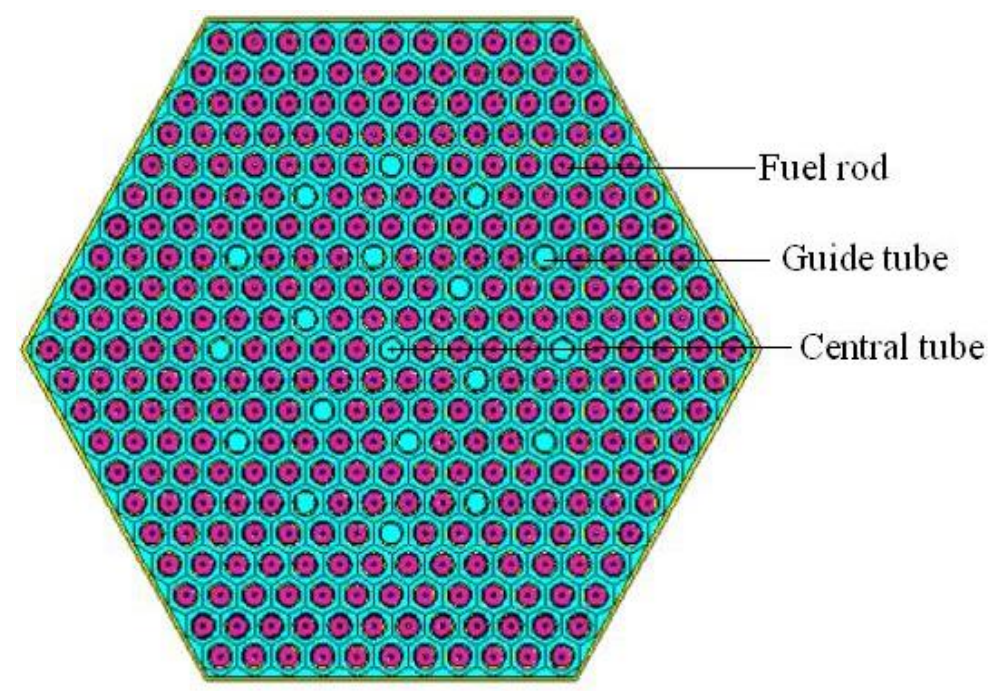

Fig. (3): Horizontal cross section of MCNPX model of VVER-1200 assembly

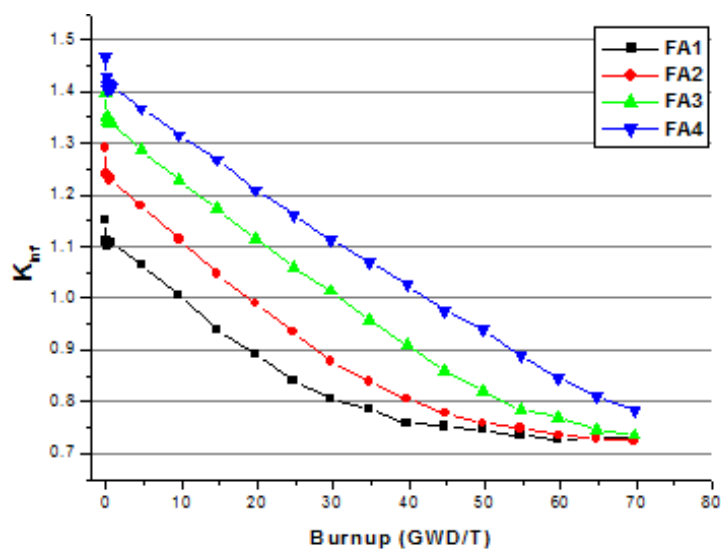

Fig. (4): Variation of the $K_{\text {inf }}$ values with burnup at different fuel enrichment

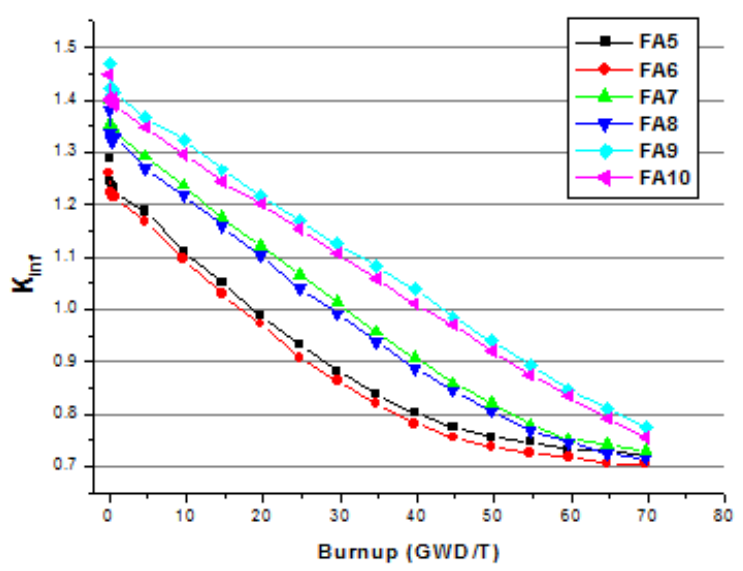

Fig. (5): Variation of the $K_{\text {inf }}$ values with burnup at different concentration of burnable poison

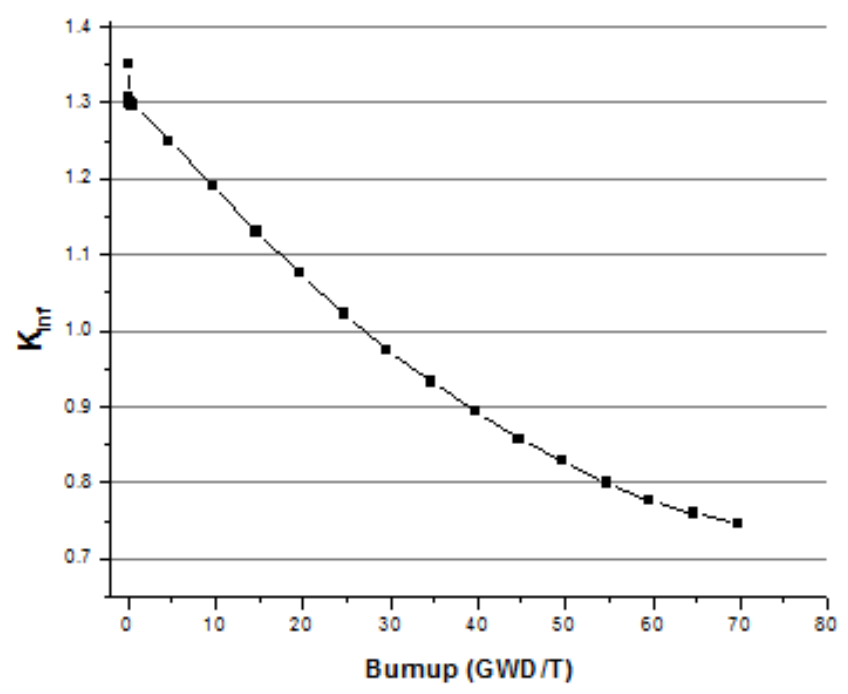

Fig. (6): Variation of the $K_{\text {inf }}$ values of the core with burnup 


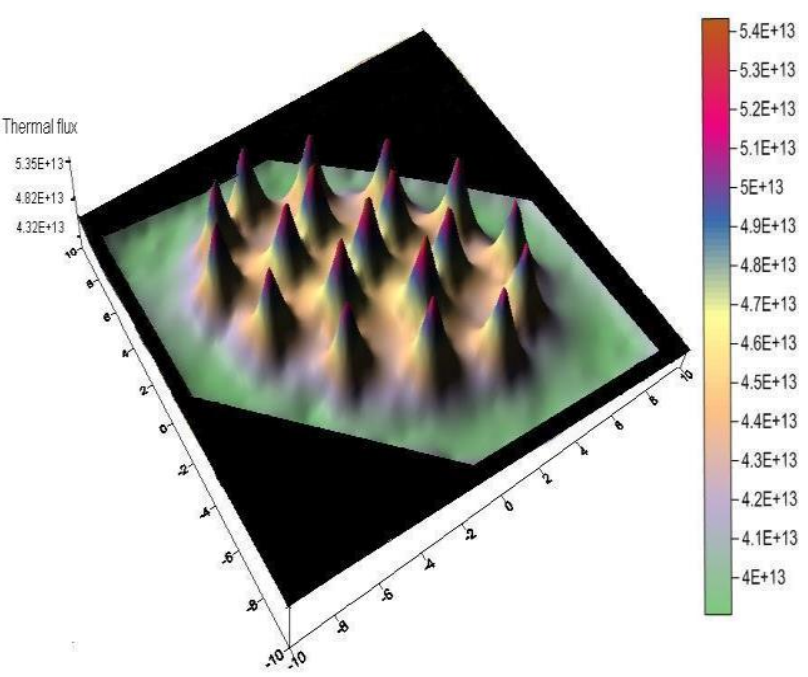

Fig. (7): Radial thermal neutron flux distribution through VVER-1200 assembly

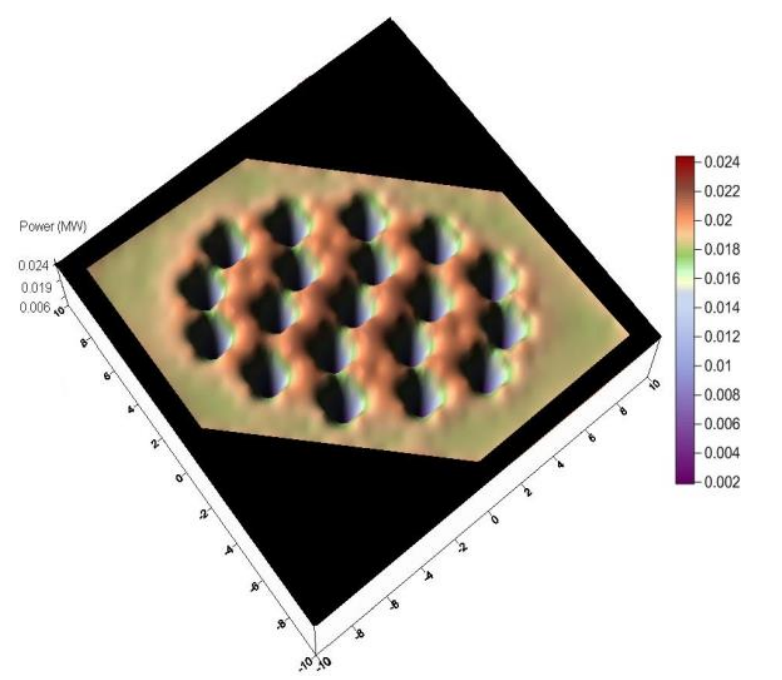

Fig. (8): Radial power distribution through VVER-1200 assembly

Table 3 Neutronics parameters of the VVER-1200 assembly at different fuel enrichment.

\begin{tabular}{c|c|c|c|c}
\hline \multirow{2}{*}{ Parameters } & \multicolumn{4}{|c}{ Fuel enrichment } \\
\cline { 2 - 5 } & $1.6 \%$ & $2.4 \%$ & $3.6 \%$ & $4.95 \%$ \\
\hline$v$ & 2.68 & 2.65 & 2.61 & 2.58 \\
Q-values (MeV) & 205.65 & 205.10 & 204.34 & 203.59 \\
$\beta_{\text {eff }}(\mathrm{pcm})$ & 811 & 699 & 637 & 595 \\
\hline
\end{tabular}

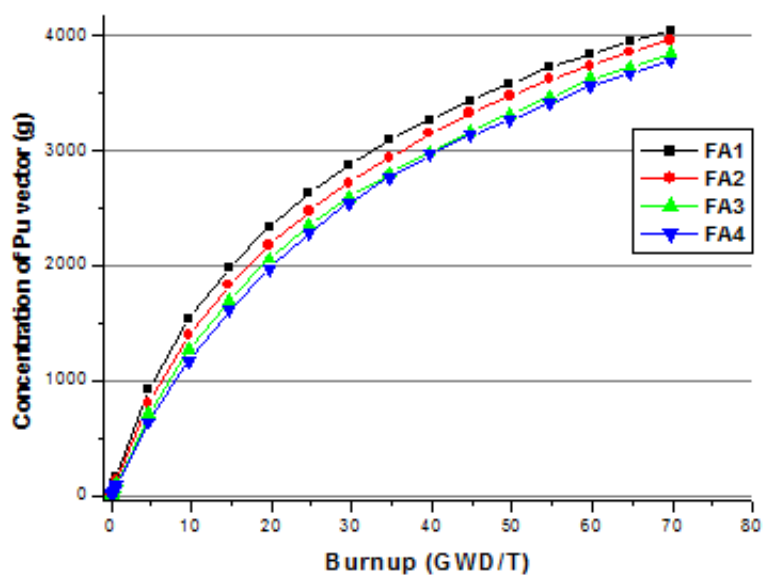

Fig. (10): Variation of the U-238/IHM (wt\%) with burnup for different fuel assembly

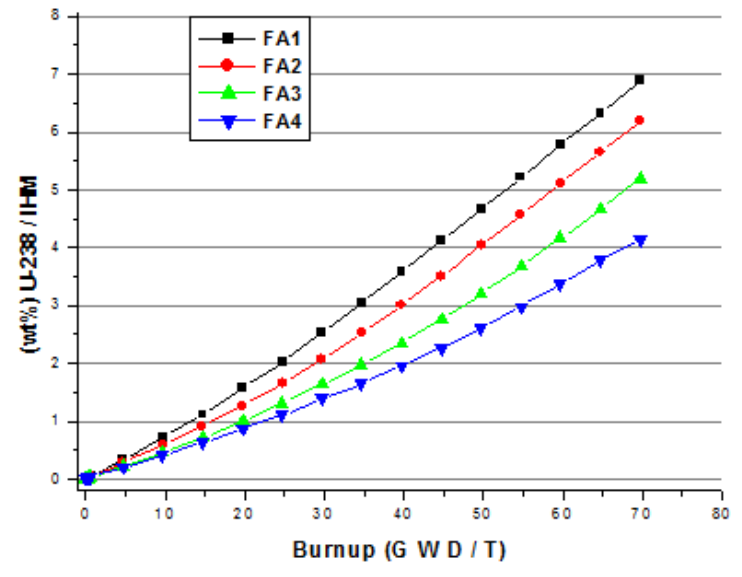

Fig. (11): Variation of the U-235/IHM (wt\%) with burnup for different fuel assembly 


\section{Void fraction}

In the VVER-1200, the void fraction may be formed as a result of two reasons; firstly, if the coolant/ moderator (water) is lost from the reactor in some types of accident (loss of coolant accident). Secondly, if the temperature inside the reactor rises, the moderator/coolant boils. This boiling leads to voids inside the reactor (steam bubbles). The author

suggested theoretically that the fuel was burnt in the existence of voids to analyze what will be happening. Fig. 12 illustrates the $K_{\text {inf }}$ of the VVER-1200 assembly fueled with $\mathrm{UO}_{2}$ with enrichment $4.95 \%$ at the different void fraction. At the begin of the cycle (BOC), the $\mathrm{K}_{\text {inf }}$ values at $20 \%$ voids are smaller than that at $0 \%$ voids while at the end of the cycle (EOC), the $\mathrm{K}_{\text {inf }}$ values at $20 \%$ voids is larger than that at $0 \%$ voids. Fig. 13 illustrates the variation of ${ }^{235} \mathrm{U} / \mathrm{IHM}$ (wt \%) concentration with burnup at the different void fraction. As the water become steam, its density decreases and its ability to slow down the fast neutrons decreases. The fast neutrons are hardly absorbed by fissile nuclei than the slow neutrons. Therefore, less number of nuclei is undergoing fission and, consequently, the $\mathrm{K}_{\text {inf }}$ values decrease at the BOC and increases at the EOC as the void fraction increases. The neutronic parameters of the VVER-1200 assembly fueled with $\mathrm{UO}_{2}$ with enrichment $4.95 \%$ at different voids are listed in Table 4. It is observed that the investigated parameter values increase when the void fraction increases. This is because the concentration of the $\mathrm{Pu}$ vector concentration increases when the void fraction increases as illustrated in Fig. 14. The void fraction inside the reactor has a significant effect on the reactivity of the reactor. Therefore, it is important to calculate the void coefficient of the reactivity. It is observed that the negative of the reactivity increase as the void fraction increases. A void coefficient of reactivity $\left(\alpha_{\mathrm{v}}\right)$ is the change in reactivity per change in the void fraction. It can be calculated using equation 3 .

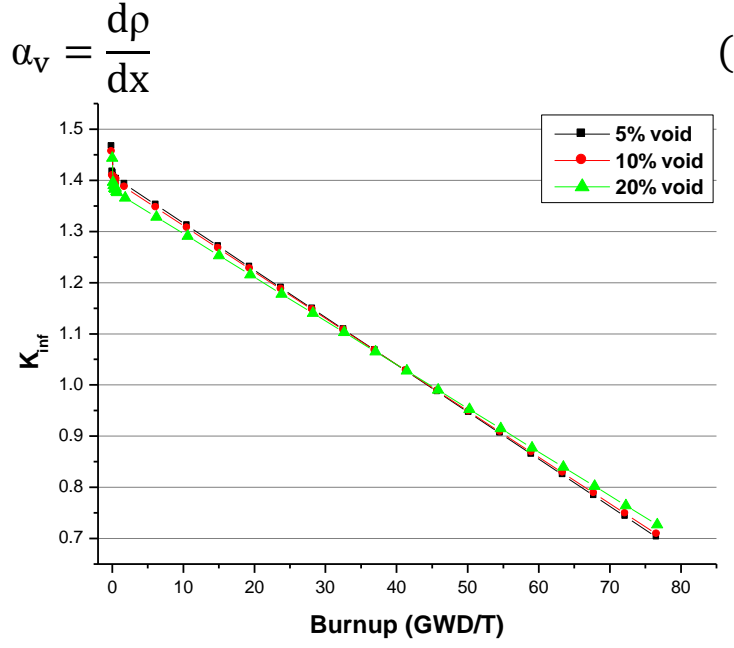

Fig. (12): Variation of the $K_{\text {inf }}$ of the VVER1200 assembly fueled with $\mathrm{UO}_{2}$ with enrichment $4.95 \%$ at the different void fraction

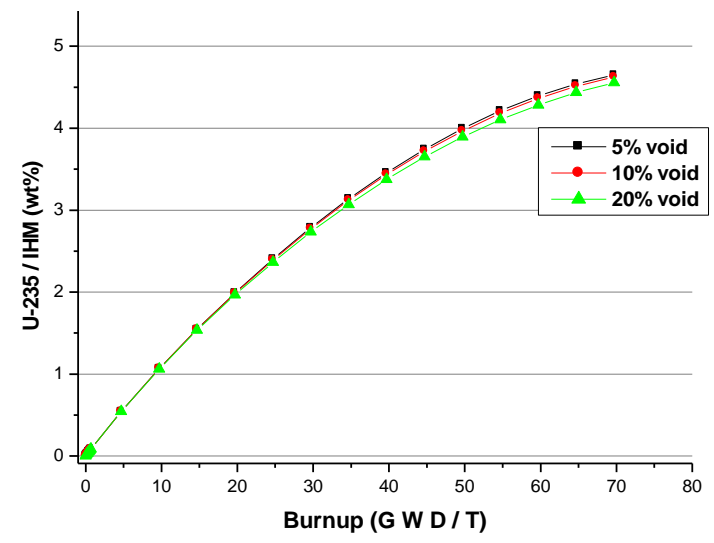

Fig. (13): Variation of the ${ }^{235} \mathrm{U} / \mathrm{IHM}$ concentration of the VVER-1200 assembly fueled with $\mathrm{UO}_{2}$ with enrichment $4.95 \%$ at the different void fraction

Table (4): Neutronics parameters of the VVER-1200 assembly at the different void percentage

\begin{tabular}{c|c|c|c}
\hline \multirow{2}{*}{ Parameters } & \multicolumn{3}{c}{ Void fraction } \\
\cline { 2 - 4 } & $5 \%$ & $10 \%$ & $20 \%$ \\
\hline$v$ & 2.582 & 2.583 & 2.584 \\
Q-values $(\mathrm{MeV})$ & 203.6 & 203.62 & 757 \\
$\beta_{\mathrm{eff}}(\mathrm{pcm})$ & 605 & 628 & -82 \\
$\alpha_{\mathrm{v}}(\mathrm{pcm} / \%)$ & -15 & -55 & \\
\hline
\end{tabular}




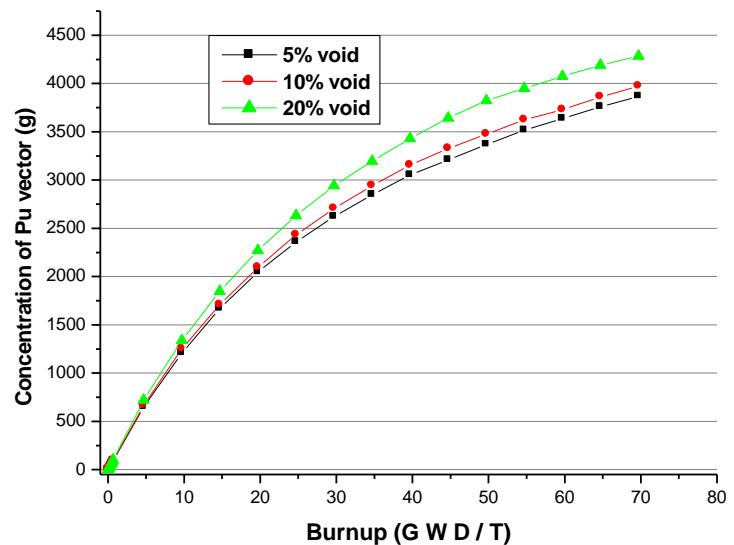

Fig. (14): Variation of the Pu vector of the VVER-1200 assembly fueled with $\mathrm{UO}_{2}$ with enrichment $4.95 \%$ at the different void fraction

\section{Burnable absorber}

The BA is a material that is used to control the nuclear fission reaction in the reactor. The BA is a strong neutron absorber that is converted into a less neutron absorbent nuclide after capturing a neutron. Two general types of BAs can be used with VVER-1200 fuels: Integral burnable absorbers (IBAs) and Burnable poison rods (BPRs). IBAs are non-removable, neutronabsorbing materials used as fixed components of a fuel assembly [10]. BPRs are rods containing neutron absorbing materials that can be inserted into the guide tubes of a VVER-1200 assembly during operation and are commonly used for reactivity control and enhancing fuel utilization. To compensate the excess reactivity present after reloading $\mathrm{UO}_{2}$ with enrichment $4.95 \%$, sufficient quantities of gadolinium were added to the fuel in the assembly or boron carbide rods were inserted into the fuel assembly. Table 5 illustrates the effect of the BAs at the different void fraction on the reactivity of the VVER-1200 assembly. The existences of gadolinium or boron carbide at BOC suppress the reactivity (i.e less quantity of ${ }^{235} \mathrm{U}$ was burnt). This negative feedback effect is one of the safety features of VVER-1200. At the EOC, the reactivity values became positive due to two reasons; firstly, the degradation of the BAs materials. Secondly, the concentration of the remaining ${ }^{235} \mathrm{U}$ with $\mathrm{BAs}$ was larger than that without BAs. The existence of the void fraction affects the reactivity of the reactor, as the thermal neutron flux decrease when the void fraction increases. At the BOC, The reactivity at $20 \%$ voids is more negative than at $0 \%$ voids while at the EOC, the reactivity at $20 \%$ voids is more positive than at $0 \%$ voids. This is due to the small quantity of ${ }^{235} \mathrm{U}$ that burnt in the case of $20 \%$ at the BOC.

The natural abundance of the ${ }^{155} \mathrm{Gd}$ equals $15 \%$, whilst the natural abundance of ${ }^{157} \mathrm{Gd}$ is $16 \%$. The neutron capture on ${ }^{155} \mathrm{Gd}$ and ${ }^{157} \mathrm{Gd}$ follows the formation of ${ }^{156} \mathrm{Gd}$ and ${ }^{158} \mathrm{Gd}$ with much lower absorption cross-sections as illustrated in Fig. 15. This process is described as gadolinium burnout. The thermal absorption cross-section of natural gadolinium exceeds fuel absorption cross-section, thus it burns faster in neutron field. The absorption cross section of ${ }^{157} \mathrm{Gd}$ for thermal neutrons is larger than fast neutron so the conversion of ${ }^{157} \mathrm{Gd}$ to ${ }^{158} \mathrm{Gd}$ at $0 \%$ voids is larger than at $20 \%$ voids.

The ability of boron carbide to absorb neutrons without forming long-lived radioactive nuclides makes it attractive as an absorbent for neutron radiation arising in nuclear power plants [11]. Natural boron contains two isotopes, namely ${ }^{10} \mathrm{~B}$ and ${ }^{11} \mathrm{~B}$. Absorption of neutron mainly relies on ${ }^{10} \mathrm{~B}$ whose thermal neutron section can be up to 3800 barns. Abundance of ${ }^{10} \mathrm{~B}$ in boron carbide for reactor should be larger than $19 \%$ and the reaction equation with neutron is

$$
{ }^{10} \mathrm{~B}+1 \mathrm{n} \rightarrow{ }^{7} \mathrm{Li}+4 \mathrm{He} .
$$

A disadvantage of boron is that it captures neutrons by an $(n, \alpha)$ reaction so that while it is in an operating reactor helium atom accumulate within the crystals of the boron carbide. These tend to form little bubbles of gas that disrupt the structure of the crystals and damage the material (swelling). This, together with the loss of the ${ }^{10} \mathrm{~B}$, limits the life of a rod used for controlling the reactor while it is operating. The absorption cross section of ${ }^{10} \mathrm{~B}$ for thermal neutrons is larger than fast neutron so the conversion of ${ }^{10} \mathrm{~B}$ to ${ }^{3} \mathrm{Li}$ at $0 \%$ voids is larger than at $50 \%$ voids as illustrated in Fig.16.

\section{Fissile inventory ratio (FIR)}

Fissile inventory ratio (FIR) is defined as the core fissile inventory at a specific time divided by the initial core fissile inventory. The FIR can be calculated by equation 4 .

$$
\operatorname{FIR}(t)=\frac{N_{\mathrm{U} 235}(t)+N_{\mathrm{Pu} 239}(t)+N_{\mathrm{Pu} 241}(t)+N_{\mathrm{Np} 239}(t)}{N_{\mathrm{U} 235}(0)+N_{\mathrm{Pu} 239}(0)+N_{\mathrm{Pu} 241}(0)+N_{\mathrm{Np} 239}(0)}
$$


$\mathrm{N}$ fissile $(\mathrm{t})$ denotes the atom density of the fissile material at a given time, and $\mathrm{N}_{\text {fissile }}(\mathrm{o})$ is the initial atom density of the fissile material. FIR (t) can be used to evaluate the breeding ability more intuitively. For uranium dioxide fuel, ${ }^{239} \mathrm{~Np}$ atoms are counted as a fissile nuclide, as in the case of core shutdown, all ${ }^{239} \mathrm{~Np}$ relatively quickly decay into fissile ${ }^{239} \mathrm{Pu}$ [12]. The FIR values are calculated for $\mathrm{UO}_{2}$ with enrichment $4.95 \%$ at the different void fraction. The FIR in the case of $0 \%$ and $20 \%$ void decrease with burnup due to the fission of the ${ }^{235} \mathrm{U}$ as illustrated in Fig.17. The variation of the coolant/moderator density affects the fission reaction rate as the coolant/moderator is the main responsible for slowing down the fast neutron until they reach the thermal energy. The fast neutron absorption cross-section of ${ }^{235} \mathrm{U}$ is very small, so less ${ }^{235} \mathrm{U}$ is burned at $20 \%$ voids than at $0 \%$ voids. The absorption cross section of ${ }^{238} \mathrm{U}$ at fast neutrons is larger than that at thermal neutrons. Therefore, more ${ }^{238} \mathrm{U}$ atoms absorb neutrons and convert to ${ }^{239} \mathrm{~Np}$ and ${ }^{239} \mathrm{Pu}$ at $20 \%$ voids than at $0 \%$ voids. Consequently, The FIR in the case of $0 \%$ voids is smaller than that in the case of $20 \%$ voids

Table (5): Effect of BAs at different void fraction on the reactivity of the VVER-1200 assembly

\begin{tabular}{c|cc|cc}
\hline \multirow{2}{*}{ Fuel cycle } & \multicolumn{4}{|c}{ Reactivity $(\mathrm{pcm})$} \\
\cline { 2 - 5 } & \multicolumn{2}{|c}{$\operatorname{IBAs}\left(3 \% \mathrm{Gd}_{2} \mathrm{O}_{3}\right)$} & \multicolumn{2}{c}{ BPRs $\left(\mathrm{B}_{4} \mathrm{C}\right)$} \\
\cline { 2 - 5 } & $0 \%$ Void & $20 \%$ Void & -20669 & $20 \%$ Void \\
\hline BOC & -10952 & -18271 & -14552 & -38025 \\
MOC & -324 & -8015 & 6923 & -25235 \\
EOC & 1161 & 6334 & & 8370 \\
\hline
\end{tabular}

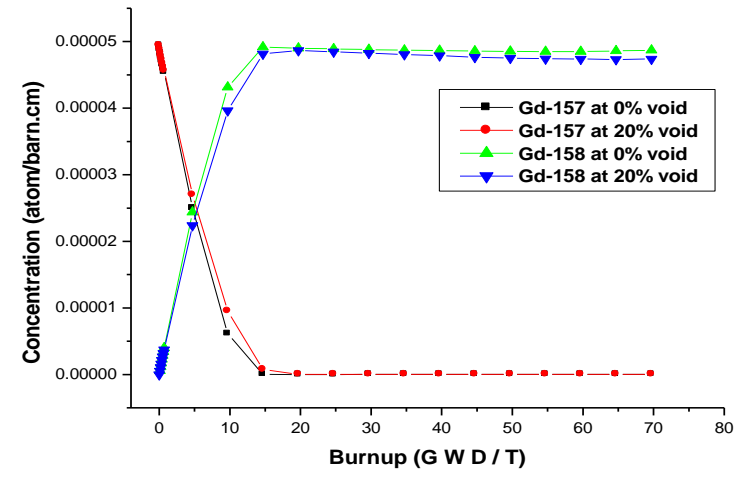

Fig. (15): Variation of the gadolinium concentration with burnup

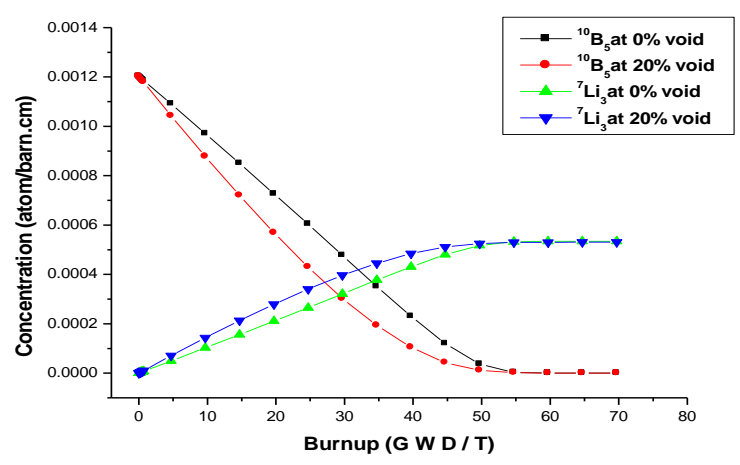

Fig. (16): Variation of the gadolinium concentration with burnup

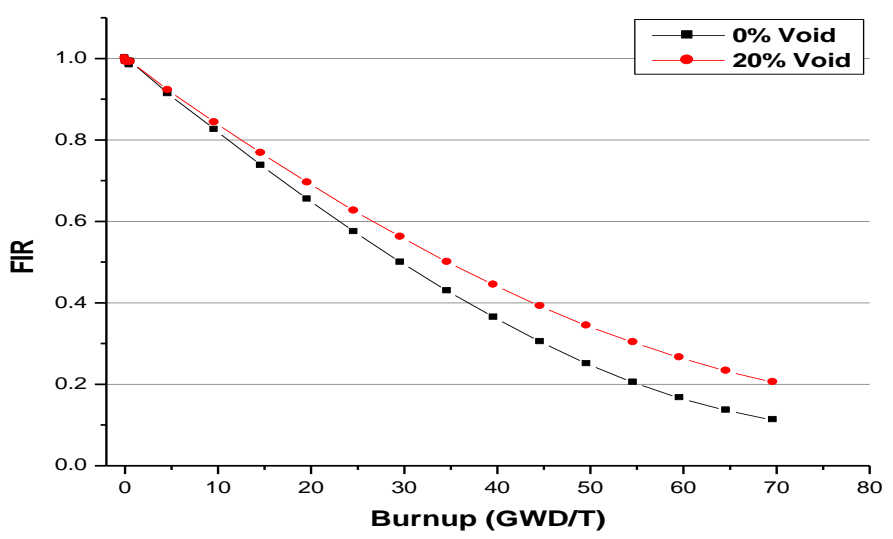

Fig. (17): Variation of the FIR with burnup at different voids 


\section{Spent fuel}

The toxicity of plutonium is significant, and a long cooling time of approximately 100,000 years is necessary for it to decay to a level below that of natural uranium. The toxicities of plutonium isotopes are generated from ${ }^{238} \mathrm{U}$. Furthermore, ${ }^{235} \mathrm{U}$ generates neptunium. However, its toxicity is negligible compared with that of natural uranium. If ${ }^{238} \mathrm{U}$ is removed from the fuel, the spent fuel has low toxicity and the cooling time to decay the toxicity to a level below that of natural uranium level might be drastically reduced to approximately 300 years [13].

Table 6 illustrates the effect of the fuel enrichment and void fraction on the TRU in the spent fuel of a VVER-1200 assembly. These elements represent the most hazardous radioactive nuclear waste products because of their long-term, high-level radioactivity. For $\mathrm{UO}_{2}$ fuel with enrichment $1.66 \%$, nearly $80 \%$ of spent fuel consists of plutonium isotopes and $20 \%$ of other TRU elements, while for $\mathrm{UO}_{2}$ fuel with enrichment $4.95 \%$, only $44.5 \%$ of spent fuel consist of plutonium isotopes. The plutonium concentration in the spent fuel depends on (a) the ${ }^{238} U$ concentration (b) The coolant or moderator density. The TRU elements concentrations were investigated for $\mathrm{UO}_{2}$ with enrichment $4.95 \%$ at different void concentration. It is observed that most of the TRU element concentration increases when the void fraction increases. ${ }^{236} \mathrm{U}$ is generally considered a nuisance and long-lived radioactive waste. It is found in spent nuclear fuel and in the reprocessed uranium made from spent nuclear fuel. ${ }^{239} \mathrm{U}$ is usually produced by exposing ${ }^{238} \mathrm{U}$ to neutron radiation in a nuclear reactor. ${ }^{239} \mathrm{U}$ decays into ${ }^{239} \mathrm{~Np}$ through beta decay. ${ }^{239} \mathrm{~Np}$ decays in a second important step that ultimately produces fissile ${ }^{239} \mathrm{Pu}$. Plutonium constitutes the majority and most dangerous component of nuclear waste.

\section{Doppler Effect}

Increasing the fuel temperature is considered one of the main problems that result from the LOCA. The fuel temperature plays an effective role in the reactivity of the reaction due to the Doppler broadening of the resonance absorption in the $\mathrm{UO}_{2}$ fuel. The Doppler reactivity coefficient is the change in the multiplication factor $\mathrm{K}_{\mathrm{inf}}$ of the system caused by variations in the fuel crosssections from temperature changes. The Doppler coefficient must be negative to be considered safe which means that the $\mathrm{k}_{\text {inf }}$ decreases as the fuel temperature increases as illustrated in Table 6 . This negativity is useful in an accident scenario in which the core overheats and the fuel temperature rises. The higher temperature causes the reactor to fission less and decrease in power.

Table (6): The composition of TRU in the spent fuel of a VVER-1200 assembly at different condition

\begin{tabular}{l|lllll}
\hline & \multicolumn{4}{|c}{ Atom concentration $(\mathrm{g})$} \\
\hline \multirow{2}{*}{ Isotopes } & \multicolumn{2}{|c}{ Fuel enrichment } & \multicolumn{2}{c}{ Void } \\
\cline { 2 - 5 } & $1.66 \%$ & $4.95 \%$ & Void 5\% & Void 20\% \\
\cline { 2 - 5 }${ }^{236} \mathrm{U}$ & $8.421 \mathrm{E}+02$ & $3.296 \mathrm{E}+03$ & $3.292 \mathrm{E}+03$ & $3.295 \mathrm{E}+03$ \\
${ }^{239} \mathrm{U}$ & $4.734 \mathrm{E}-01$ & $3.780 \mathrm{E}-01$ & $3.775 \mathrm{E}-01$ & $3.659 \mathrm{E}-01$ \\
${ }^{237} \mathrm{~Np}$ & $1.205 \mathrm{E}+02$ & $2.916 \mathrm{E}+02$ & $3.079 \mathrm{E}+02$ & $3.457 \mathrm{E}+02$ \\
${ }^{238} \mathrm{Pu}$ & $6.810 \mathrm{E}+01$ & $2.257 \mathrm{E}+02$ & $2.346 \mathrm{E}+02$ & $2.655 \mathrm{E}+02$ \\
${ }^{239} \mathrm{Pu}$ & $8.551 \mathrm{E}+02$ & $9.728 \mathrm{E}+02$ & $1.032 \mathrm{E}+03$ & $1.260 \mathrm{E}+03$ \\
${ }^{240} \mathrm{Pu}$ & $1.201 \mathrm{E}+03$ & $1.247 \mathrm{E}+03$ & $1.273 \mathrm{E}+03$ & $1.321 \mathrm{E}+03$ \\
${ }^{241} \mathrm{Pu}$ & $4.463 \mathrm{E}+02$ & $4.999 \mathrm{E}+02$ & $5.338 \mathrm{E}+02$ & $6.428 \mathrm{E}+02$ \\
${ }^{242} \mathrm{Pu}$ & $1.414 \mathrm{E}+03$ & $8.343 \mathrm{E}+02$ & $8.317 \mathrm{E}+02$ & $7.956 \mathrm{E}+02$ \\
\hline
\end{tabular}

Table (6): Doppler reactivity coefficient at different temperature

\begin{tabular}{|c|c|}
\hline Temperature $(\mathrm{k})$ & Doppler reactivity coefficient $(\mathrm{pcm} / \mathrm{k})$ \\
\hline 400 & -331.48 \\
\hline 600 & -482.903 \\
\hline 900 & -513.557 \\
\hline 1200 & -784.153 \\
\hline
\end{tabular}




\section{Conclusion}

A model of MCNPX for VVER-1200 has been designed and applied for void fraction analysis. This model has been used to investigate the variation of the $K_{\text {inf }}$ at different fuel assembly enrichment and different void fraction. It is observed that the variation of the $v, Q$ and $\beta_{\text {eff }}$ values depends on the $\mathrm{Pu}$ isotopes concentrations that are breeding with burnup. The presence of voids in the reactor increases the production of the $\mathrm{Pu}$ isotopes. It is found that the FIR values increases when the void fraction increases. This is because two reasons; the first, a small quantity of ${ }^{235} \mathrm{U}$ undergoes fission as the void fraction increases. The second, the presences of void fractions increase the breeding of $\mathrm{Pu}$ isotopes. The presence of void fraction with either IBAs or BPRs increases the negativity of the reaction. The effect of the void fraction on the $\mathrm{B}_{4} \mathrm{C}$ is larger than $\mathrm{Gd}_{2} \mathrm{O}_{3}$. The occurrence of the void fraction leads to increase the fuel temperature, consequently, the negativity of the Doppler coefficient of VVER1200 increases. The concentration of the most hazard radioactive nuclear waste increases when the void fraction increases,

\section{References}

1. Obaidurrahman, K., Doshi, J.B. (2011) Spatial instability analysis in pressurized water reactors. Annals of Nuclear Energy. 38, 286294.

2. Status report 108 - VVER-1200 (V-491) (VVER-1200 (V-491)).

3. Nikitin, K., Mueller, P., Martin, J., Doesburg, W.V., Hiltbrand, D. (2016) BWR loss of coolant accident simulation by means of RELAP5. Nuclear Engineering and Design. 309, 113-121.

4. Rassame, S., Hibiki, T., Ishii, M. (2017) ESBWR passive safety system performance under loss of coolant accidents. Progress in Nuclear Energy. 96, 1-17.

5. Yu, S.O., Cho, Y.J., Kim, S.J. (2017) Effect of emergency core cooling system flow reduction on channel temperature during recirculation phase of large break loss-of-coolant accident at wolsong unit 1. Nuclear Engineering and Technology. 49, 5, 979-988.

6. Risovany,V.D., Varlashova,E.E., Suslov, D.N. (2000) Dysprosium titanate as an absorber material for control rods. Journal of Nuclear Materials. 281, 84-89.

7. Sahin, S., Ahmed, R., Khan, M.J. (2012) Assessment of criticality and burn up behavior of candu reactors with nuclear waste trans uranium fuel. Progress in Nuclear Energy. 60, 19-26.

8. Mozafari, M.A., Faghihi, F. (2013) Design of annular fuels for a typical VVER-1000 core: Neutronic investigation, pitch optimization and MDNBR calculation. Annals of Nuclear Energy. 60, 226-234.

9. Bretscher, M.M. (1997) Evaluation of reactor kinetic parameters without the need for perturbation codes. International Meeting on Reduced Enrichment for Research and Test Reactors. Argonne National Laboratory, Illinois 60439-4841. Jackson Hole, Wyoming, USA.

10. Galahom, A.A. (2017) Study of the possibility of using Europium and Pyrex alloy as burnable absorber in PWR. Annals of Nuclear Energy. 110, 1127-1133.

11. Sokhansanj, A., Hadian, A.M. (2012) Purification of Attrition Milled Nano-size Boron Carbide Powder. 2nd International Conference on Ultrafine Grained \& Nanostructured Materials. International Journal of Modern Physics: Conference Series. 5, 94101.

12.Liu, S., Cai, J. (2013) Convergence analysis of neutronic/ thermohydraulic coupling behavior of SCWR. Nuclear Engineering and Design. 265, 53- 62 .

13. Fukaya, Y., Goto, M., Nishihara, T. (2015) Study on erbium loading method to improve reactivity coefficients for low radiotoxic spent fuel HTGR. Nuclear Engineering and Design. 293, 30-37. 